Article

\title{
Meanings and Interpretations of Spirituality in Nursing and Health
}

\author{
Nasreen Lalani $(\mathbb{D}$ \\ School of Nursing, Purdue University, West Lafayette, IN 47907, USA; lalanin@purdue.edu
}

Received: 28 June 2020; Accepted: 14 August 2020; Published: 21 August 2020

\begin{abstract}
Numerous spirituality models and tools have been developed in health education and research, but a gap still exists around the conceptual clarity and articulation of spirituality among nurses and healthcare providers. Nurses and healthcare providers still find it difficult to interpret and apply the concepts of spirituality in their practice settings. This paper provides a concept analysis of spirituality using the Walker and Avant method of conceptual analysis. Several databases including conceptual and empirical literature from various disciplines have been used. The defining attributes of spirituality included spirituality and religion as a separable or mutual construct, spirituality as a personal construct, wholeness and integration, meaning making and purpose, sense of connectedness and relationship, transcendence, inner source of power, energy, and strength. Major antecedents of spirituality found were faith, personal values, and belief systems, and life adversities. Consequences of spirituality included personal/spiritual growth and wellbeing, resilience, and religiousness. Spirituality is a unique and personal human experience, an individualised journey characterised by multiple experiential accounts such as meaning making, purpose, connectedness, wholeness and integration, energy, and transcendence. Spiritual experiences are often difficult to examine and measure using scientific tools and empirical language. Healthcare providers need to fully understand and apply spirituality and spiritual care aspects to provide holistic person-centred care.
\end{abstract}

Keywords: spirituality; concept analysis; personal human experience; transcendence; faith; culture

Spirituality has been an evolving concept in nursing and health disciplines over the last three decades. Recent literature indicates that spirituality is a broader concept than religion (Cohen et al. 2012; McSherry and Ross 2004; Sessanna et al. 2007). However, for some individuals and communities, spiritualty is still experienced and expressed in terms of religious values, faith, and belief (Cohen et al. 2012). Bash (2004) states that spirituality is a personal construct and every person has his/her own definition of spirituality influenced by personal beliefs and value systems. Chiu et al. (2004) suggest for a cross-cultural examination of the term 'spirituality' to understand its commonality and specificity in different cultural contexts. The constant debate and multiple perspectives around the definitions of spirituality present multiple challenges for health practitioners, educators, and researchers when examining, interpreting, and applying spirituality in their own settings (Cohen et al. 2012; Swinton and Pattison 2010; Lewinson et al. 2015). A recent literature review by Ali et al. (2018) found several gaps in knowledge and practice of spirituality in nursing. The authors identified issues of conceptual clarity and articulation around the ontological and phenomenological aspects of nursing including spiritual and existential issues that need to be addressed to prepare nurses and healthcare practitioners for holistic care. A conceptual clarity and contextual understanding of various dimensions and actual meanings and interpretations of spirituality among nurses and healthcare providers is critical to create a deeper understanding and application of the concept and bringing effective health and research outcomes (McSherry and Draper 1998; Swinton and Pattison 2010). Further examination of the term spirituality will allow an in-depth interpretation of the concept from diverse perspectives and help in identifying some common themes among this diversity. 
The following paper aims to conduct a conceptual analysis of the term spirituality to examine and develop an in-depth understanding of the meanings and interpretation of spirituality in nursing and health using Walker and Avant's (2005) eight steps of conceptual analysis. These steps include: select a concept, determine the aims or purposes of analysis, determine the defining attributes and characteristics, identify antecedents and consequences, identify all uses of the concept, identify a model case, and define empirical referents. The paper examines the concept of spirituality and builds upon the previous conceptual analysis done in the nursing and health literature. Such an approach allowed researcher to view how spirituality has evolved in nursing and health while also determining varied meanings and interpretations of spirituality across different contexts and cultures. A clear and broader understanding of the concept will allow healthcare practitioners, educators, and researchers to internalize the significance of spirituality and embrace spiritual care aspects in their practice settings.

\section{Background}

This section presents conceptual analysis of spirituality carried out in the past by multiple researchers in the last three decades. Within nursing literature, the first concept analysis found was conducted by Burkhardt (1989) who described spiritualty as an inner strength, unfolding mystery and harmonious interconnectedness between self, others, or a higher being such as God. According to her, spirituality is an inherent aspect of a human being, an experience that can be expressed with or without religion or religious practices. Similarly Dyson et al. (1997); Emblen (1992), and Meraviglia (1999) also viewed spiritualty distinct from religion. The experiences and expressions of one's spirit is a unique and dynamic process, and involves an integration of the dimensions of mind, body, and spirit (Meraviglia 1999). Most authors took a humanistic perspective in defining spirituality and argued that spirituality is a personal construct, a sense of being. It is the individual that assigns the meaning and values to spirituality. Tanyi (2002) stated that the sense of connectedness is self-chosen that inspires individuals to achieve their optimal being and these connections may or may not be limited to some higher power, supernatural or omnipotent. The spiritual needs and expressions may vary among people in different contexts and cultures and can expressed in several ways other than religious rituals and practices such as art, music, drama, nature, etc. (Koenig et al. 2001; Tanyi 2002). Spirituality can be expressed through showing love, being present, listening, and communication (Egan et al. 2011). Newlin et al. (2002) using Rogerian approach analysed the concept of spirituality from an African American context and asserted that spirituality is both personal and context dependent. In their study, spirituality is viewed as faith in an omnipotent God, or higher power, a transcendent force. According to the authors, spirituality was manifested as an 'empowering transformation' and 'liberating consolation' for life's adversities while having a strong belief and faith in the benevolent source of unlimited potential (p. 65). Spirituality is viewed around religion and religious values (Newlin et al. 2002; Zinnbauer et al. 1997). Similar findings were also reported by Lalani et al. (2019) in their study of spiritual experiences among Muslim family caregivers at the end of life where spirituality was expressed as firm belief in God, religious values, and beliefs. Family caregivers' spiritual experiences of love and belongingness, respect and honour, altruistic and compassionate values, and a firm belief in God helped them to transcend their worries and life adversities to achieve self-transformation and personal growth. Sessanna et al. (2007) asserted that spirituality and religion are mutual concepts, and therefore cannot be separated. The authors stressed the importance of having a contextual understanding of spirituality as in some cultures, individuals' personal and spiritual experiences, beliefs, and values are shaped by their religion traditions and customs. These values are reflected in their daily lives, health behaviours and actions and therefore, need to be given priority. On the contrary, (Delgado 2005; Buck 2006) argued that spirituality goes beyond religious or cultural boundaries. It may or may not involve religious structures, theistic traditions, or beliefs, it is a personal human experience that seeks to transcend self and find meaning and purpose (Rovers and Kocum 2010). Similarly, Weathers and Coffey (2015) expressed spirituality in terms of meaning making, connectedness, and transcendence beyond self, 
everyday living, and suffering. Withers et al. (2017) argue that spirituality encompasses a broad belief system that included human rights, personal values, religion, and culture.

The above discussion shows that spirituality remains an elusive concept, the existing definitions and meanings of spirituality are too broad, abstract, and context dependent. Pesut (2008) argues that spirituality is a personal construct and encompasses a broad belief system therefore, using a generic approach to understand spirituality may cause ambiguity and confusion. Most spiritual assessment tools, models, and spiritual care guidelines are developed in the west and therefore are not necessarily applicable in the other contexts (Lalani et al. 2018). It is therefore critical to understand and analyse the concept of spirituality from various perspectives for its better application in education and practice settings.

\section{Methodology}

The term 'spirituality' was searched in the literature using the following databases: CINAHL, MEDLINE, PSYC-info, ATLA Religion, and EMBASE. Several databases allowed the researcher to examine the term spirituality within medicine, nursing, philosophy, socio-anthropology, religion, and psychological perspectives. Moreover, the meaning of spirituality was looked for in various dictionaries, online sources including websites, and books. The following keywords were used for the search; spirit, spiritual, spirituality, nursing, health, definition, meaning, theory, and concept analysis. The initial search using various sources showed a total of 986 articles/search papers from the period of 1990 to 2019. The search was further refined to academic and peer reviewed journals, published in English language, papers mainly describing a conceptual analysis of spirituality, meanings of spirituality, integrated reviews of spirituality, and evidenced based articles describing the spiritual experiences or spirituality. A manual search was conducted that included further examining of the references for spirituality in the published articles. At this stage, 258 articles were considered relevant. After reviewing the titles and abstracts of various articles, 155 articles were selected for review for the purposes of this paper. Both conceptual and empirical articles defining the term spirituality were included. There is a possibility that using articles in English language may have restricted search criteria to different cultures/contexts, religions, and study design. (See Figure 1).

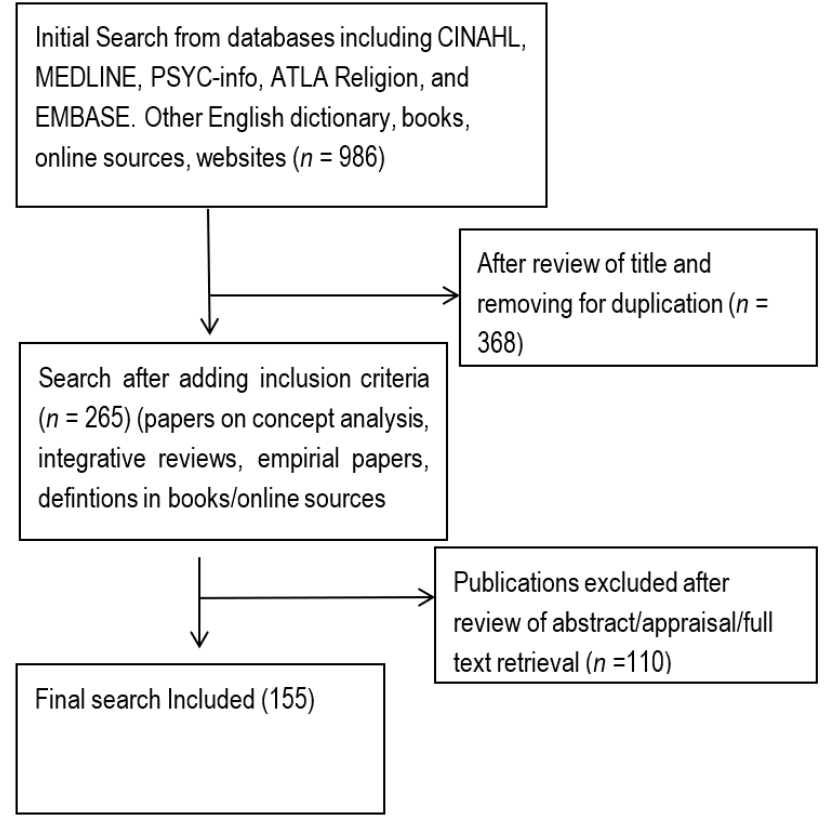

Figure 1. Search process. 


\section{Defining Attributes of Spirituality}

Spirituality is derived from the Latin root 'spiritus', which means breath, inspiration, character, or the soul (Chiu et al. 2004; Delgado 2005). In Hebrew, Greek, and Roman cultures, the spirit was termed as the 'breath of life'. There are many other words used for spirit as 'psyche' in Greek, 'atman' in Sanskrit, and 'ruach' in Hebrew (Delgado 2005). Various dictionary definitions were searched to describe the meaning of spirituality. Terms like spirit and spiritual were found in the dictionary. The concise Oxford dictionary (1990) defines spirit as "the vital animating essence of a person or animal, the intelligent non- physical part of a person, the soul, a rational or intelligent being without a material body, supernatural being such as a ghost or fairy" whereas spiritual is defined as "something that is concerned with sacred or religious things, holy, divine, refined, sensitive, not concerned with the material, concerned with the soul or spirit etc. not with external reality". According to Merriam-Webster Online Dictionary (2015), the word spirit means "the force within a person that is believed to give the body life, energy and power". It is also defined as "the inner quality or nature of a person" and is often termed as 'essence', 'psyche' or 'soul' whereas spirituality was defined as "the quality or sate of being concerned with religion or religious matters, the quality or state of being spiritual".

Several authors have defined spirituality using various approaches and perspectives. The common themes found after analysing several definitions of spirituality included: spirituality and religion-separable or mutual constructs, spirituality as a personal construct, integration and wholeness, meaning making and purpose, sense of connectedness and relationships, transcendence and inner source of power, energy, and strength. Several definitions gathered from the search are given in Table 1.

\section{Spirituality and Religion: Separable or Mutual Constructs}

Some authors defined spirituality within the realm of religion (Zinnbauer et al. 1997) while others believed that spirituality is a broader concept (Buck 2006; Cohen et al. 2012; Delgado 2005; Dyson et al. 1997; Emblen 1992; McSherry and Ross 2004; Sessanna et al. 2007). Among several authors, religion is seen as an organized system of beliefs, a prescribed set of practices, rituals, and symbols, more of a communal practice (Narayanasamy 2004), whereas spirituality is seen as an individual human experience (King and Koenig 2009). Several authors argue that spirituality is a personal quest for meaning of life and religion serves as a way to express spirituality (Koenig et al. 2001; Tanyi 2002). Spirituality is a journey and religion serve a way that takes us through this journey (Narayanasamy 2004). Empirical studies indicate that for the majority of people, it is difficult to separate religion from spirituality (Koenig 2009; Moberg 2010; Sessanna et al. 2007). Spirituality is commonly expressed in forms of religious beliefs, rituals, and practices among people and religious scholars in different cultural settings (Asgeirsdottir et al. 2013; Dedeli et al. 2015; Kristjanson et al. 1997; Rahimi et al. 2013).

\section{Spirituality Is a Personal Construct}

Every human is spiritual (Agrimson and Taft 2009); spirit is a vital essence of a person, a person's true self, and an inherent aspect of every human being (Buck 2006; Burkhardt and Nagai-Jacobson 2002; Martsolf and Mickley 1998). Spirituality reflects one's individuality without having any affiliation to any religious group or tradition (Bessinger and Kuhne 2002; Daaleman 2004). The sense of meaning making is an individualized and a personal phenomenon, and therefore can only be realized or experienced by the individual person (Dyson et al. 1997; Mok et al. 2010). 


\section{Integration and Wholeness}

Spirituality is a personal journey towards integration or wholeness (Meraviglia 1999; O'Brien 2014). It is a "glue" that keeps together all other dimensions of human such as physical, psychological, social, and cultural (Malinski 2002) and promotes a sense of responsibility, engagement, intimacy, wholeness, and spiritual wellbeing (Walton 1996).

\section{Meaning Making and Purpose}

Spirituality is the essence of our being that provides the meaning and purpose to our existence (Narayanasamy 2004; O'Brien 2014); such meanings could be philosophical, religious, humanist, secular, or personal in nature (Büssing et al. 2014; O'Brien 2014). It is a sacred and existential journey, a core human value that provides a sense of worth, dignity, and a reason for living (Davison and Jhangri 2010; Eliason et al. 2010).

\section{Sense of Connectedness and Relationship}

Spirituality is one's connectedness to self, to others, the metaphysical, to the transcendent, and a unifying principle in the universe (Burkhardt 1989; Burkhardt and Nagai-Jacobson 2002; Walton 1996). It could be a harmonious intellectual connection between individuals and their spiritual thoughts (Weber and Pargament 2014). Walton (1996) argues that the depth or intimacy of the relationship is directly related to the individual's personal knowledge of self or soul-searching. Evidence suggests that a strong sense of connectedness brings faith, hope, and peace, and promotes personal growth, wellbeing, and empowerment (Markani et al. 2013; Lalani et al. 2018).

\section{Transcendence}

Spirituality is a personal search or a transcendent experience (Reed 1992; Vachon 2008; Yuen 2007). Self-transcendence refers to reaching beyond personal boundaries to attain a wider perspective and to find meaning in life's experiences (Coward and Reed 1996). Such an experience can be intrapersonal, interpersonal, or transpersonal (Reed 1992). It is mystical in nature and therefore difficult to examine using scientific tools or using empirical language (Bash 2004; Sessanna et al. 2007).

\section{Antecedents of Spirituality}

Antecedents are events that must be present before the occurrence of a concept (Walker and Avant 2005). The antecedents of spirituality include faith, personal values, belief systems, and life adversities.

\section{Faith}

Faith is defined as believing in your own personal values and beliefs and is not limited to any religious or theistic beliefs or traditions. Faith guides individual action and thoughts and assist them to find meaning and purpose in life (Carey and Cohen 2008).

\section{Personal Values and Belief Systems}

Spirituality is embodied within an individual's beliefs and experiences, shaping our meanings and define goals in our lives (Pesut 2008; Johnstone et al. 2012). Communal spirituality is often guided by values such as altruism and service to others, often found among people following a monotheistic religion (Hodge and Sun 2012; Isgandarova and O'Connor 2012).

\section{Life Adversities}

Sufferings and life adversities such as aging, illness, dying, loss or grief, and disasters generate spiritual awakening and self-reorganization (Agrimson and Taft 2009; Ahmad et al. 2011; Asgeirsdottir et al. 2013; Deal 2011; Puchalski 2007, 2013). Evidence also suggest that such experiences can alter a person's attitudes towards life, their sense of coherence, decision making, and coping 
abilities (Daaleman et al. 2008; Hanson et al. 2008; Mok et al. 2010; Puchalski 2007, 2013). However, a constant debate is found in the literature over these conclusions.

\section{Consequences of Spirituality}

Consequences are events or incidents that emerge as a result of the concept (Walker and Avant 2005). The consequences of spirituality found are personal growth and wellbeing, resilience, and religiousness.

\section{Personal Growth and Wellbeing}

Evidence suggests that spirituality enables individuals to endure suffering and assist them to find meaning and purpose in challenging times, which can ultimately turn into a transcendent experience and bring personal growth (Agrimson and Taft 2009; Ahmad et al. 2011; Asgeirsdottir et al. 2013; Deal 2011; Lalani et al. 2019).

\section{Resilience}

Spirituality may bring a positive outlook and resilience that raises the person's ability to thrive with uncertainty and find strength in adapting successfully during periods of stress, illness, or any crisis situation (Anandarajah 2008; Delgado 2005).

\section{Religiousness}

The literature supports that some religiousness may be an outcome of spirituality (Alcorn et al. 2010; Meraviglia 1999; Zinnbauer et al. 1997), however not all individuals follow religion or are religious and thus, the particular notion requires further inquiry. Empirical studies suggest that religious beliefs and practices enable individuals to create meaningful worldviews, reflect on their own spiritualties and find meaning for their own spiritual actions and thoughts (Taylor 2003). Prayer, meditation, or church attendance generate self-awareness and provide a better understanding of one's own values and beliefs (Anandarajah 2008). It is noteworthy that most of these studies were done among people who practiced some form of religion or religious practices.

\section{Uses of the Concept in Nursing}

Spirituality is an essence of caring and carry a strong historical significance in nursing. Connell Meehan (2012) reports images of nurses found some 7000 years ago during the Indo-European era that symbolizes the spirit of care, and protection of human life. Across seven millennia, the focus of nursing remained spiritual, fostering health and healing across different cultures (Tyler and Raynor 2006). Early nursing textbooks defined nursing as serving and caring for humanity; the primary role of the nurse is to restore harmony between mind, body, and spirit (O'Brien 2014). Several nursing theories signify spirituality as an important dimension of holistic care Neuman's Systems model, Parse's theory of human becoming, Watson's theory of caring, person-centred care framework, and several others. Due to technological advancements and the influence of bio-medical models of health, the notion of spirituality was ignored. During the last two decades, spirituality has received special attention in nursing education, practice, and research, as evidenced by a large number of studies on spirituality within the nursing discipline (Sessanna et al. 2011). Newer models and approaches emphasize integrating spirituality and spiritual care within nursing curricula and practice (Lewinson et al. 2015). The International Council of Nursing (ICN 2012) and the Joint Commission on Accreditation of Healthcare Organizations (JCAHO) stress integrating spirituality as an essential aspect of care and emphasize assessing and respecting spiritual beliefs of patients and their families in the healthcare setting (Bashar et al. 2018). Several authors have identified the need for developing spiritual care competencies among nurses to improve provision of spiritual care in the clinical care settings (Ali et al. 2018; McSherry 2006). 


\section{Model Case}

A model case contains all the defining attributes, some of the antecedents, and consequences of spirituality (Walker and Avant 2005). Ms. K is a middle-aged, working woman and a single parent living with her two boys, nine and seven years old. She is a schoolteacher and loves to be around children, caring for and helping others. She also serves as a parent counsellor in her school. When she was only 14 years old, her parents died in a car accident. Since then she lived with her aunts and uncles. She completed high school and passed her teaching diploma while also doing causal and part-time jobs. She got divorced after five years of her marriage and now she is the sole earning member of the family with two young kids. Her seven-year-old son is autistic and requires close attention and care. She believes that continuous struggle and adversities in her life has transformed her into a strong and resilient woman. She has close ties with her neighbours who help her in some of her household chores and care activities. She is actively engaged in community-based childcare activities. She finds meaning, peace, and love in her work, service, and family.

\section{Defining Empirical Referents}

It is difficult to appraise spirituality from a single empirical indicator (Meraviglia 1999). The common empirical referents of the term spirituality are spiritual wellbeing, subjective wellbeing, spiritual health, and quality of life. Faith and prayers are other indicators used to define spirituality. Spirituality is also assessed by using various meaning making, compassion, emotional and psychological wellbeing scales. Spiritual wellbeing scales (SWB) developed by Paloutzian and Ellison (1982) has been frequently used in the quantitative research. Other spiritual scales include: Spiritual Beliefs Inventory (SBI) developed by Holland et al. (1998), Spiritual Involvement and Beliefs Scale (SIBS) developed by Hatch et al. (1998); and the Functional Assessment of Chronic Illness Therapy-Spiritual Well-Being (FACIT-SP) developed by Peterman et al. (2002) are commonly used scales in the literature. Several authors have also used qualitative approaches such as in-depth interviews, narratives, and personal stories to explore the personal human experiences of spirituality.

\section{Discussion}

Spirituality is a complex phenomenon; several meanings, attributes, antecedents, and consequences related to the concept provide a wider and richer understanding of the concept. The conceptual analysis indicate that spirituality is a continuously evolving concept, a broader concept than religion and other theistic beliefs. Most authors have used humanistic approach, defining spirituality as a unique and personal human experience, an individualised journey characterised by experiential descriptors such as meaning, purpose, connectedness, wholeness and integration, energy, and transcendence. In contrast, religion is characterised by institutionalised beliefs and rituals, mostly relegated to a subset of either spirituality or culture (Pesut 2008). The argument still follows that within some cultures and faith traditions, spirituality is still experienced in a communal context, seen in close relationships with others who share similar beliefs and experiences (Hodge and Sun 2012; Rahnama et al. 2012) or seen as a transcendent experience with higher/supreme being. For many, spirituality cannot be separated from religion; religion and spirituality should be considered as a mutual construct. Being a health practitioner, it is essential to acknowledge religious and spiritual values of patients and families that might play an essential role in healthcare decision making. Evidence also suggests that spiritual experiences vary among individuals and are context dependent. Spiritual experiences are often influenced by one's personal life experiences, development processes, values and beliefs, religion, and culture, and therefore should not be ignored. The person-centred care approach allows addressing patient/family spiritual needs and values; most spiritual models are developed in the west and tend to ignore some of the diverse characteristics and meanings of spirituality that are highly valued from an eastern perspective. 
Spirituality is seen as relational in many cultures and societies and family love and values from essential aspects of inner spiritualty Drawn from the analysis, the consequences of spirituality such as personal growth, acts of altruism and service for others are highly valued in eastern cultures and communities, and thus can be viewed as major sources to empower and develop resilience and wellbeing of patients and families in the research and practice settings (Lalani et al. 2019). The application of spirituality and spiritual care concepts are not limited to the clinical or health settings, but can also be applied in environmental, social work, occupational health, and other disciplines. The constructs of spirituality have been recently explored and utilized in higher education to develop meaning making among students and faculty, strategize personal and professional mentoring activities, and generate compassionate values and leadership potential (Ali and Snowden 2019). Evidence also suggests that there are personal and mystical spiritual experiences such as experiences of awe, ecstasy and transcendence, often difficult to measure and quantify using scientific models and language of empiricism that are simply not relevant (Bash 2004). Such experiences and related meanings require further inquiry, unfolding and clarification. Linguistic limitations have also been reported to fully understand the meanings and concepts of spirituality in different settings and therefore need further inquiry and research (Narayanasamy 1999; Lomas 2019).

\section{Conclusions}

Spirituality is a complex subjective human experience, is context dependent and encompasses a broad belief system. An individual can experience spirituality in several forms. For some, spirituality is about their personal values/traits. For others, it may be relational, an experience of the transcendent, personal growth or spiritual transformation, religious/theistic values and beliefs or service to others. Spirituality is a human development process that involves experiences of meaning making, connectedness, and transcendence. Health is the harmony between mind, body, and soul. To achieve this harmony, it is important to understand and value human experiences of spirituality across different cultures and contexts. As healthcare providers, we must adopt a person-centred holistic approach to care to protect the health and wellbeing of the people.

Table 1. Definitions of spirituality and underlying themes.

\begin{tabular}{|c|c|c|c|}
\hline Author & Year & Definition & Theme \\
\hline Burkhardt & 1989 & $\begin{array}{l}\text { Spiritualty as the inner strength, unfolding mystery } \\
\text { and harmonious interconnectedness. }\end{array}$ & $\begin{array}{l}\text { Inner strength, mystery, } \\
\text { connectedness }\end{array}$ \\
\hline Emblen & 1992 & $\begin{array}{l}\text { A dynamic, principle, or an aspect of the person } \\
\text { that relate to God or god, other persons, or aspects } \\
\text { of personal being or material nature. }\end{array}$ & $\begin{array}{l}\text { Relationship/ } \\
\text { connectedness }\end{array}$ \\
\hline Reed & 1992 & $\begin{array}{l}\text { rRfers to the propensity to make meaning through } \\
\text { a sense of relatedness to dimensions that transcend } \\
\text { the self in such a way that empowers and does not } \\
\text { devalue the individual. } \\
\text { This relatedness may be experienced } \\
\text { intrapersonally (as a connectedness within oneself), } \\
\text { interpersonally (in the context of others and the } \\
\text { natural environment), and transpersonally } \\
\text { (referring to a sense of relatedness to the unseen, } \\
\text { God, or power greater than the self and ordinary } \\
\text { resources) (p. 350) }\end{array}$ & $\begin{array}{l}\text { Meaning making, and } \\
\text { transcendence }\end{array}$ \\
\hline Walton & 1996 & $\begin{array}{l}\text { A spiritual relationship may be a relationship to } \\
\text { self, others, a higher power, or nature in which one } \\
\text { behaves humanistically, has a sense of } \\
\text { responsibility and personal identity, and describes } \\
\text { the relationship as producing intimacy, wholeness, } \\
\text { and wellness (p. } 242 \text { ). }\end{array}$ & $\begin{array}{l}\text { Connectedness, intimacy, } \\
\text { wholeness and wellness }\end{array}$ \\
\hline
\end{tabular}


Table 1. Cont.

\begin{tabular}{|c|c|c|c|}
\hline Author & Year & Definition & Theme \\
\hline Zinnbauer et al. & 1997 & $\begin{array}{l}\text { Spirituality is interrelated to religion. Spirituality } \\
\text { toward God is considered to be the primary focus } \\
\text { of one's spirit, and the other remaining forms of } \\
\text { connectedness are therefore considered } \\
\text { to be secondary. }\end{array}$ & $\begin{array}{l}\text { Connectedness to God is } \\
\text { (Primary) whereas } \\
\text { Connectedness to others } \\
\text { (Secondary) }\end{array}$ \\
\hline Dyson et al. & 1997 & $\begin{array}{l}\text { Spirituality was conceived most often as the right } \\
\text { relationship between self, others, and God. }\end{array}$ & $\begin{array}{l}\text { Connectedness/ } \\
\text { relationship }\end{array}$ \\
\hline Meraviglia & 1999 & $\begin{array}{l}\text { Spirituality is the experiences and expressions of } \\
\text { one's spirit in a unique and dynamic process } \\
\text { reflecting faith in God or a supreme being; } \\
\text { connectedness with oneself, others, nature or God; } \\
\text { and integration of the dimensions of mind, body, } \\
\text { and spirit }\end{array}$ & $\begin{array}{l}\text { Faith, connectedness, } \\
\quad \text { integration }\end{array}$ \\
\hline Kim \& Lee & 1998 & $\begin{array}{l}\text { Spirituality as a basic human attribute which gives } \\
\text { meaning to life, it's a relationship between the } \\
\text { omnipotent and the supernatural and with others. } \\
\text { It is also a source of human power. }\end{array}$ & $\begin{array}{l}\text { Meaning making, } \\
\text { connectedness, human } \\
\text { power }\end{array}$ \\
\hline Tanyi & 2002 & $\begin{array}{l}\text { Spirituality involves humans' search for meaning } \\
\text { in life }\end{array}$ & Meaning making \\
\hline Newlin et al. & 2002 & $\begin{array}{l}\text { African-American spirituality is faith in an } \\
\text { omnipotent, God, or higher power, a transcendent } \\
\text { force. Spirituality is experienced as an } \\
\text { interconnectedness with others, God, or a higher } \\
\text { power and manifested as an 'empowering } \\
\text { transformation of' and 'liberating consolation for } \\
\text { life's adversities'. It pursues a strong belief and } \\
\text { faith in the benevolent source of unlimited } \\
\text { potential (p. 65). }\end{array}$ & $\begin{array}{l}\text { Faith, connectedness, } \\
\quad \text { transcendence }\end{array}$ \\
\hline McSherry et al. & 2004 & Did not provided any definition & \\
\hline Narayanasamy & 2004 & $\begin{array}{l}\text { The essence of our being and it gives meaning and } \\
\text { purpose to our existence }\end{array}$ & \\
\hline Bash & 2004 & $\begin{array}{l}\text { Spirituality is therefore an elastic, subjective } \\
\text { description about a person and about the way they } \\
\text { express their humanity. For some this may be to do } \\
\text { with values; for others, an experience of the } \\
\text { transcendent. For some it may be to do with } \\
\text { personal growth; for others about prayer. }\end{array}$ & $\begin{array}{l}\text { Transcendence, personal } \\
\text { values, personal growth }\end{array}$ \\
\hline Buck & 2006 & $\begin{array}{l}\text { Spiritualty is a human experience that seeks to } \\
\text { transcend self and find meaning and purpose } \\
\text { through connection with others, nature, and/or a } \\
\text { Supreme Being. }\end{array}$ & $\begin{array}{l}\text { Transcendence, meaning } \\
\text { making and purpose }\end{array}$ \\
\hline Yuen & 2007 & $\begin{array}{l}\text { A more personal search for transcendent } \\
\text { understanding that may or may not include } \\
\text { activities within organized groups. }\end{array}$ & Transcendence \\
\hline Pesut & 2008 & $\begin{array}{l}\text { Spirituality as an individualised journey } \\
\text { characterised by experiential descriptors such as } \\
\text { meaning, purpose, transcendence, connectedness } \\
\text { and energy. } \\
\text { Religion, characterised by institutionalised beliefs } \\
\text { and rituals, has in some instances been relegated to } \\
\text { a subset of either spirituality or culture. }\end{array}$ & $\begin{array}{l}\text { Meaning, purpose, } \\
\text { transcendence, } \\
\text { connectedness and } \\
\text { energy }\end{array}$ \\
\hline
\end{tabular}


Table 1. Cont.

\begin{tabular}{|c|c|c|c|}
\hline Author & Year & Definition & Theme \\
\hline Vachon & 2008 & $\begin{array}{l}\text { That which allows a person to experience } \\
\text { transcendent meaning in their life }\end{array}$ & \\
\hline Alcorn et al. & 2010 & $\begin{array}{c}\text { A search for or a connection to what is divine or } \\
\text { sacred" and religion defined as "a tradition of } \\
\text { spiritual beliefs and practices shared by a group of } \\
\text { people." }\end{array}$ & Connectedness \\
\hline Hodge \& Sun & 2012 & $\begin{array}{l}\text { Spirituality is a human search for the sacred that } \\
\text { typically occurs in a community context with } \\
\text { others who share similar beliefs and experiences. }\end{array}$ & Connectedness \\
\hline Delgado & 2013 & $\begin{array}{l}\text { Spirituality is characterized by faith, a search for } \\
\text { meaning and purpose in life, a sense of connection } \\
\text { with others, and a transcendence of self, resulting } \\
\text { in a sense of inner peace and well-being. }\end{array}$ & $\begin{array}{l}\text { Faith, search for } \\
\text { meaning, purpose, } \\
\text { connectedness, } \\
\text { transcendence }\end{array}$ \\
\hline Markani et al. & 2013 & $\begin{array}{l}\text { Spirituality is the core of a person's being and is } \\
\text { usually conceptualised as a 'higher' experience or a } \\
\text { transcendence of oneself }\end{array}$ & Transcendence \\
\hline Asgeirsdottir et al. & 2013 & Spirituality as a meaning of life & Meaning making \\
\hline Weathers et al. & 2015 & $\begin{array}{l}\text { Spirituality is a way of being in the world in which } \\
\text { a person feels a sense of connectedness to self, } \\
\text { others, and/or a higher power or nature; a sense of } \\
\text { meaning in life; and transcendence beyond self, } \\
\text { everyday living, and suffering. }\end{array}$ & $\begin{array}{l}\text { Connectedness, meaning } \\
\text { and transcendence }\end{array}$ \\
\hline
\end{tabular}

Funding: This research received no external funding.

Conflicts of Interest: The author declares no conflict of interest.

\section{References}

Agrimson, Laurie B., and Lois B. Taft. 2009. Spiritual crisis: A concept analysis. Journal of Advanced Nursing 65: 454-61. [CrossRef] [PubMed]

Ahmad, Farizah, Mazanah binti Muhammad, and Amini Amir Abdullah. 2011. Religion and Spirituality in Coping with Advanced Breast Cancer: Perspectives from Malaysian Muslim Women. Journal of Religion $\mathcal{E}$ Health 50: 36-45. [CrossRef]

Alcorn, Sara R., Michael J. Balboni, Holly G. Prigerson, Amy Reynolds, Andrea C. Phelps, Alexi A. Wright, Susan D. Block, John R. Peteet, Lisa A. Kachnic, and Tracy A. Balboni. 2010. If God wanted me yesterday, I wouldn't be here today: Religious and spiritual themes in patients' experiences of advanced cancer. Journal of Palliative Medicine 13: 581-88. [CrossRef] [PubMed]

Ali, Gulnar, and Michael Snowden. 2019. SOPHIE (Self-Exploration Through Ontological, Phenomenological, Humanistic, Ideological and Existential Expressions): A Mentoring Framework. In Mentorship, Leadership, and Research. Cham: Springer, pp. 107-16.

Ali, Gulnar, Michael Snowden, John Wattis, and Melanie Rogers. 2018. Spirituality in nursing education: Knowledge and practice gaps. International Journal of Multidisciplinary Comparative Studies 5: 27-49.

Anandarajah, Gowri. 2008. The $3 \mathrm{H}$ and BMSEST models for spirituality in multicultural whole-person medicine. Annals of Family Medicine 6: 448-58. [CrossRef] [PubMed]

Asgeirsdottir, Gudlaug Helga, Einar Sigurbjörnsson, Rannveig Traustadottir, Valgerdur Sigurdardottir, Sigridur Gunnarsdottir, and Ewan Kelly. 2013. To cherish each day as it comes: A qualitative study of spirituality among persons receiving palliative care. Supportive Care in Cancer Official Journal of the Multinational Association of Supportive Care in Cancer 21: 1445-51. [CrossRef]

Bash, Anthony. 2004. Spirituality: The emperor's new clothes? Journal of Clinical Nursing 13: 11-16. [CrossRef] 
Bashar, Farshid R., Amir Vahedian-Azimi, Mahmood Salesi, Mohammadreza Hajiesmaeili, Seyedpouzhia Shojaei, Behrooz Farzanegan, Reza Goharani, Seyed J. Madani, Kivan G. Moghaddam, Sevak Hatamian, and et al. 2018. Spiritual health and outcomes in Muslim ICU patients: A nationwide cross-sectional study. Journal of Religion and Health 57: 2241-57. [CrossRef]

Bessinger, Donivan, and Trey Kuhne. 2002. Medical spirituality: Defining domains and boundaries. Southern Medical Journal-Birmingham Alabama 95: 1385-88. [CrossRef]

Buck, Harleah G. 2006. Spirituality: Concept analysis and model development. Holistic Nursing Practice 20: $288-92$. [CrossRef]

Burkhardt, Margaret A. 1989. Spirituality: An analysis of the concept. Holistic Nursing Practice 3: 69-77. [CrossRef] [PubMed]

Burkhardt, Margaret A., and Mary Gail Nagai-Jacobson. 2002. Spirituality: Living Our Connectedness. Albany: Delmar/Thomson Learning.

Büssing, Arndt, Klaus Baumann, Niels Christian Hvidt, Harold G. Koenig, Christina M. Puchalski, and John Swinton. 2014. Spirituality and health. Evidence Based Complement Alternative Medicine 2014: 682817. [CrossRef] [PubMed]

Carey, Lindsay B., and Jeffrey Cohen. 2008. Religion, spirituality and health care treatment decisions: The role of chaplains in the Australian clinical context. Journal of Health Care Chaplain 15: 25-39. [CrossRef] [PubMed]

Chiu, Lyren, Julia D Emblen, Lynn Van Hofwegen, Rick Sawatzky, and Heather Meyerhoff. 2004. An integrative review of the concept of spirituality in the health sciences. Western Journal of Nursing Research 26: 405-28. [CrossRef]

Cohen, Marlene Z., Lyn M. Holley, Steven P. Wengel, and Katzman Rabbi Mendel. 2012. A platform for nursing research on spirituality and religiosity: Definitions and measures. Western Journal of Nursing Research 34: 795-817. [CrossRef]

Connell Meehan, Therese. 2012. Spirituality and spiritual care from a careful nursing perspective. Journal of Nursing Management 20: 990-1001. [CrossRef]

Coward, Doris D., and Pamela G. Reed. 1996. Self-transcendence: A resource for healing at the end of life. Issues in Mental Health Nursing 17: 275-88. [CrossRef]

Daaleman, Timothy P. 2004. Religion, spirituality, and the practice of medicine. The Journal of the American Board of Family Practice 17: 370-76. [CrossRef]

Daaleman, Timothy P., Barbara M Usher, Sharon W Williams, Jim Rawlings, and Laura C Hanson. 2008. An exploratory study of spiritual care at the end of life. Annals of Family Medicine 6: 406-11. [CrossRef]

Davison, Sara N., and Gian S. Jhangri. 2010. Existential and religious dimensions of spirituality and their relationship with health-related quality of life in chronic kidney disease. Clinical Journal of American Society of Nephrology 5: 1969-76. [CrossRef]

Deal, Belinda. 2011. Finding meaning in suffering. Holistic Nursing Practice 25: 205-10. [CrossRef] [PubMed]

Dedeli, Ozden, Emel Yildiz, and Safak Yuksel. 2015. Assessing the Spiritual Needs and Practices of Oncology Patients in Turkey. Holistic Nursing Practice 29: 103-13. [CrossRef] [PubMed]

Delgado, Cheryl. 2005. A discussion of the concept of spirituality. Nursing Science Quarterly 18: 157-62. [CrossRef] [PubMed]

Dyson, Jane, Mark Cobb, and Dawn Forman. 1997. The meaning of spirituality: A literature review. Journal of Advanced Nursing 26: 1183-88. [CrossRef]

Egan, Richard, Rod MacLeod, Chrystal Jaye, Rob McGee, Joanne Baxter, and Peter Herbison. 2011. What is spirituality? Evidence from a New Zealand hospice study. Mortality 16: 307-24. [CrossRef]

Eliason, Grafton T., Jeff L. Samide, George Williams, and Mark F. Lepore. 2010. Existential theory and our search for spirituality. Journal of Spirituality in Mental Health 12: 86-111. [CrossRef]

Emblen, Julia D. 1992. Original article: Religion and spirituality defined according to current use in nursing literature. Journal of Professional Nursing 8: 41-47. [CrossRef]

Hanson, Laura C., Debra Dobbs, Barbara M. Usher, Sharon Williams, Jim Rawlings, and Timothy P. Daaleman. 2008. Providers and types of spiritual care during serious illness. Journal of Palliative Medicine 11: 907-14. [CrossRef]

Hatch, Robert L., Mary Ann Burg, Debra S. Naberhaus, and Linda K. Hellmich. 1998. The spiritual involvement and beliefs scale. Journal of Family Practice 46: 476-86. 
Hodge, David R., and Fei Sun. 2012. Positive feelings of caregiving among Latino Alzheimer's family caregivers: Understanding the role of spirituality. Aging \& Mental Health 16: 689-98. [CrossRef]

Holland, Jimmie C., Kathryn M. Kash, Steven Passik, Melissa K. Gronert, Antonio Sison, Marguerite Lederberg, Simcha M. Russak, Lea Baider, and Bernard Fox. 1998. A brief spiritual beliefs inventory for use in quality of life research in life-threatening illness. Psycho-Oncology: Journal of the Psychological, Social and Behavioral Dimensions of Cancer 7: 460-69. [CrossRef]

International Council of Nurses. 2012. The ICN Code of Ethics. Rev. Available online: https://www.icn.ch/sites/ default/files/inline-files/2012_ICN_Codeofethicsfornurses_\%20eng.pdf (accessed on 30 June 2020).

Isgandarova, Nazila, and Thomas St James O'Connor. 2012. A redefinition and model of Canadian Islamic spiritual care. The Journal Of Pastoral Care E Counseling 66: 7.

Johnstone, Brick, Dong Pil Yoon, Daniel Cohen, Laura H. Schopp, Guy McCormack, James Campbell, and Marian Smith. 2012. Relationships among spirituality, religious practices, personality factors, and health for five different faith traditions. Journal of Religion and Health 51: 1017-41. [CrossRef] [PubMed]

King, Michael B., and Harold G. Koenig. 2009. Conceptualising spirituality for medical research and health service provision. BMC Health Services Research 9: 116. [CrossRef] [PubMed]

Koenig, Harold G. 2009. Research on religion, spirituality, and mental health: A review. Canadian Journal of Psychiatry 54: 283-91. [CrossRef] [PubMed]

Koenig, Harold G., Michael E. McCullough, and David B. Larson. 2001. Handbook of Religion and Health. Oxford and New York: Oxford University Press.

Kristjanson, Linda J., Anne Leis, Priscilla M. Koop, K. C. Carriere, and Bryan Mueller. 1997. Family members' care expectations, care perceptions, and satisfaction with advanced cancer care: Results of a multi-site pilot study. Journal of Palliative Care 13: 5-13. [CrossRef]

Lalani, Nasreen, Wendy Duggleby, and Joanne Olson. 2018. Spirituality among family caregivers in palliative care: An integrative literature review. International Journal of Palliative Nursing 24: 80-91. [CrossRef]

Lalani, Nasreen, Wendy Duggleby, and Joanne Olson. 2019. Rise Above: Experiences of Spirituality Among Family Caregivers Caring for Their Dying Family Member in a Hospice Setting in Pakistan. Journal of Hospice $\mathcal{E}$ Palliative Nursing 21: 422-29.

Lewinson, Lesline P., Wilfred McSherry, and Peter Kevern. 2015. Spirituality in pre-registration nurse education and practice: A review of the literature. Nurse Education Today 35: 806-14. [CrossRef]

Lomas, Tim. 2019. The dynamics of spirituality: A cross-cultural lexical analysis. Psychology of Religion and Spirituality 11: 131. [CrossRef]

Malinski, Violet M. 2002. Developing a nursing perspective on spirituality and healing. Nursing Science Quarterly 15: 281-87. [CrossRef] [PubMed]

Markani, Abdolah Khorami, Farideh Yaghmaei, and Mohammad Khodayari Fard. 2013. Spirituality as experienced by Muslim oncology nurses in Iran. British Journal of Nursing 22: S22-S28. [CrossRef] [PubMed]

Martsolf, Donna S., and Jacqueline R. Mickley. 1998. The concept of spirituality in nursing theories: Differing world-views and extent of focus. Journal of Advanced Nursing 27: 294-303. [CrossRef] [PubMed]

McSherry, Keith Cash, and Linda Ross. 2004. Meaning of spirituality: Implications for nursing practice. Journal of Clinical Nursing 13: 934-41. [CrossRef]

McSherry, Wilfred, and Peter Draper. 1998. The debates emerging from the literature surrounding the concept of spirituality as applied to nursing. Journal of Advanced Nursing 27: 683-91. [CrossRef]

McSherry, Wilfred. 2006. Making Sense of Spirituality in Nursing and Health Care Practice: An Interactive Approach. London: Jessica Kingsley Publishers.

Meraviglia, Martha G. 1999. Critical analysis of spirituality and its empirical indicators prayer and meaning in life. Journal of Holistic Nursing 17: 18-33. [CrossRef]

Merriam-Webster Online Dictionary. 2015. Available online: https://www.merriam-webster.com/thesaurus/spirit (accessed on 15 February 2020).

Moberg, David O. 2010. Spirituality research: Measuring the immeasurable. Perspectives on Science and Christian Faith 62: 99-114.

Mok, Esther, Frances Wong, and Daniel Wong. 2010. The meaning of spirituality and spiritual care among the Hong Kong Chinese terminally ill. Journal of Advanced Nursing 66: 360-70. [CrossRef]

Narayanasamy, Aru. 1999. A review of spirituality as applied to nursing. International Journal of Nursing Studies 36: 117-25. [CrossRef] 
Narayanasamy, Aru. 2004. The puzzle of spirituality for nursing: A guide to practical assessment. British Journal of Nursing 13: 1140-44. [CrossRef]

Newlin, Kelley, Kathleen Knafl, and Gail D’Eramo Melkus. 2002. African-American spirituality: A concept analysis. Advances in Nursing Science 25: 57-70. [CrossRef] [PubMed]

O'Brien, Mary Elizabeth. 2014. Spirituality in Nursing: Standing on Holy Ground/Mary Elizabeth O'Brien, 5th ed. Burlington: Jones \& Bartlett Learning.

Paloutzian, Raymond F., and Craig W. Ellison. 1982. Loneliness, spiritual well-being and the quality of life. In Loneliness: A Sourcebook of Current Theory, Research and Therapy: Current Theory, Research, and Therapy. Edited by L. A. Peplau and D. Perlman. New York: John Wiley \& Sons, pp. 224-37.

Pesut, Barbara. 2008. A conversation on diverse perspectives of spirituality in nursing literature. Nursing Philosophy 9: 98-109. [CrossRef]

Peterman, Amy H., George Fitchett, Marianne J. Brady, Lesbia Hernandez, and David Cella. 2002. Measuring spiritual well-being in people with cancer: The functional assessment of chronic illness therapy-Spiritual Well-being Scale (FACIT-Sp). Annals of Behavioral Medicine 24: 49-58. [CrossRef] [PubMed]

Puchalski, Christina M. 2007. Spirituality and the Care of Patients at the End-of-Life: An Essential Component of Care. Omega: Journal of Death \& Dying 56: 33-46. [CrossRef]

Puchalski, Christina M. 2013. Integrating spirituality into patient care: An essential element of person-centered care. Polish Archives of Internal Medicine 123: 491-97. [CrossRef] [PubMed]

Rahimi, Abolfazl, Monireh Anoosheh, Fazlollah Ahmadi, and Mahshid Foroughan. 2013. Exploring spirituality in Iranian healthy elderly people: A qualitative content analysis. Iranian Journal of Nursing and Midwifery Research 18: 163-70.

Rahnama, Mozhgan, Masoud Fallahi Khoshknab, Sadat Seyed Bagher Maddah, and Fazlollah Ahmadi. 2012. Iranian cancer patients' perception of spirituality: A qualitative content analysis study. BMC Nursing 11: 19-26. [CrossRef]

Reed, Pamela G. 1992. An emerging paradigm for the investigation of spirituality in nursing. Research in Nursing and Health 15: 349-57. [CrossRef]

Rovers, Martin, and Lucie Kocum. 2010. Development of a holistic model of spirituality. Journal of Spirituality in Mental Health 12: 2-24. [CrossRef]

Sessanna, Loralee, Deborah Finnell, and Mary Ann Jezewski. 2007. Spirituality in nursing and health-related literature: A concept analysis. Journal of Holistic Nursing 25: 252-62, discussion 263-54. [CrossRef]

Sessanna, Loralee, Deborah S Finnell, Meghan Underhill, Yu-Ping Chang, and Hsi-Ling Peng. 2011. Measures assessing spirituality as more than religiosity: A methodological review of nursing and health-related literature. Journal Advanced Nursig 67: 1677-94. [CrossRef] [PubMed]

Swinton, John, and Stephen Pattison. 2010. Moving beyond clarity: Towards a thin, vague, and useful understanding of spirituality in nursing care. Nursing Philosophy 11: 226-37. [CrossRef] [PubMed]

Tanyi, Ruth A. 2002. Towards clarification of the meaning of spirituality. Journal of Advanced Nursing 39: 500-9. [CrossRef]

Taylor, Elizabeth Johnston. 2003. Spiritual needs of patients with cancer and family caregivers. Cancer Nursing 26: 260-66. [CrossRef] [PubMed]

Tyler, Indira D., and James E. Raynor Jr. 2006. Spirituality in the natural sciences and nursing: An interdisciplinary perspective. ABNF Journal 17: 63. [PubMed]

Vachon, Mary L.S. 2008. Meaning, Spirituality, and Wellness in Cancer Survivors. Seminars in Oncology Nursing 24: 218-25. [CrossRef]

Walker, Lorraine Olszewski, and Kay Coalson Avant. 2005. Strategies for Theory Construction in Nursing. Upper Saddle River: Prentice Hall.

Walton, Joni. 1996. Spiritual relationships: A concept analysis. Journal of Holistic Nursing 14: 237-50. [CrossRef]

Weathers, Elizabeth Geraldine McCarthy, and Alice Coffey. 2015. Concept analysis of spirituality: An evolutionary approach. Nursing Forum 51: 79-96. [CrossRef]

Weber, Samuel R., and Kenneth I. Pargament. 2014. The role of religion and spirituality in mental health. Current Opinion in Psychiatry 27: 358-63. [CrossRef]

Withers, Alexandrea, Kimberly Zuniga, and Sharon L. Van Sell. 2017. Spirituality: Concept analysis. International Journal of Nursing \& Clinical Practices 4: 234-39. 
Yuen, Elaine J. 2007. Spirituality, religion, and health. American Journal of Medical Quality 22: 77-79. [CrossRef] [PubMed]

Zinnbauer, B. J., K. I. Pargament, B. Cole, M. S. Rye, E. M. Butter, T. G. Belavich, and J. L. Kadar. 1997. Religion and spirituality: Unfuzzying the fuzzy. Journal for the Scientific Study of Religion 36: 549-64. [CrossRef] 